\title{
Evaluación de la eficiencia de extractos vegetales y agentes microbiológicos para el control del barrenador de la naranjilla Neoleucinodes elegantalis
}

\section{Evaluation of the efficiency of plant extracts and microbiological agents in the control of naranjilla fruit screwworm Neoleucinodes elegantalis}

\author{
María Belén Ledesma ${ }^{1}$, Carlos Alberto Ortega ${ }^{1}$, Patricio Gallegos ${ }^{2}$, Juan Pazmiño ${ }^{1}$ \\ ${ }^{1}$ Universidad Central del Ecuador. Facultad de Ciencias Agrícolas. Carrera de Ingeniería Agronómica. Jerónimo Leiton y Av. La Gasca s/n. Ciudadela \\ Universitaria. 170521 Quito, Ecuador ${ }^{2}$ Departamento de Protección Vegetal, INIAP-Santa Catalina
}

\begin{abstract}
Resumen
En la Estación Experimental "Santa Catalina" del Instituto Nacional Autónomo de Investigaciones Agropecuarias (INIAP) se realizaron pruebas de mortalidad de huevecillos y larvas de primer instar del barrenador de la naranjilla (Neoleucinodes elegantalis) utilizando extractos vegetales y agentes microbiológicos para así determinar un nivel representativo de control para ambas variables. Los tratamientos que mayor mortalidad presentaron fueron evaluados en campo para determinar la capacidad de control de Neoleucinodes elegantalis en el cultivo de naranjilla (Solanum quitoense). La evaluación se la realizó durante cuatro cosechas consecutivas en la parroquia de Río Negro en la provincia de Tungurahua. Los resultados encontrados determinaron que (Vertigo ${ }^{\circledR} 3.8 \mathrm{~cm}^{3} / \mathrm{dm}^{3}$ ) + (Ac. Piñón $5 \mathrm{~cm}^{3} / \mathrm{dm}^{3}$ ) presentó un porcentaje de control de $51.41 \%$ seguido de Bacillus thuringiensis (CustomBio BT $2.5 \mathrm{~cm}^{3} / \mathrm{dm}^{3}$ ) con un control de 50.56\%.
\end{abstract}

Palabras clave: Solanum quitoense, porcentaje de fruta sana, pruebas de mortalidad, Galleria mellonella.

\begin{abstract}
Mortality test on Galleria mellonella first-istar eggs and larvae of Neoleucinodes elegantalis were conducted at the "Santa Catalina" Experimental Station at the Autonomous National Institute for Agriculture Research (INIAP), using plant extracts and microbiological agents in order to establish a representative mortality sample for both variables. The treatments that showed higher mortality were evaluated in the field to determinate the control capacity of Neoleucinodes elegantalis in the naranjilla (Solanum quitoense) crops. The evaluation was carried out during four consecutive harvests at the parish of Rio Negro in the province of Tungurahua. The results show that (Vertigo $\left.{ }^{\circledR} 3.8 \mathrm{~cm}^{3} / \mathrm{dm}^{3}\right)+\left(\right.$ Ac. Pinion $\left.5 \mathrm{~cm}^{3} / \mathrm{dm}^{3}\right)$ showed a control percentage of $51.41 \%$ followed by Bacillus thuringiensis (BT CustomBio $2.5 \mathrm{~cm}^{3} / \mathrm{dm}^{3}$ ) with a control percentage of $50.56 \%$
\end{abstract}

Keywords: Solanum quitoense, biological control, percentage of healthy fruit, mortality tests, Galleria mellonela. 


\section{Introducción}

El cultivo de la naranjilla es considerado de gran importancia económica para los pueblos ubicados en la región amazónica, en provincias como: Napo, Pastaza, Morona Santiago, Sucumbíos, Zamora Chinchipe y Orellana (Ruiz, 2013). Este cultivo al establecerse en zonas que poseen condiciones climáticas de alta temperatura y humedad relativa presenta susceptibilidad al ataque constante de plagas, mismas que generan pérdidas de 226 ha (169 ha por ataque de plagas y 57 ha por fitopatógenos) (INEC-MAG-SICA, 2012).

El barrenador o gusano del fruto Neoleucinodes elegantalis (Guenée, 1854) (Lepidóptera: Crambidae) presenta una incidencia elevada, por lo que es considerado de control obligatorio y representa una de las más importantes limitaciones en cuanto al cultivo de naranjilla, debido a que causa daño directo al fruto, incrementa los costos de control y genera pérdidas de producción en hasta un 90\% (Fiallos, 2000).

Actualmente, el manejo de plagas en el cultivo de naranjilla pone en riesgo el bienestar ambiental y la salud de los productores dedicados a este cultivo, debido al uso inadecuado y exagerado de pesticidas altamente tóxicos (Revelo et al, 2010). Por el comportamiento propio de esta plaga la alternativa química para controlar al barrenador del fruto no es eficiente (Molina \& Manzano, 2012). En cuanto a control biológico para el barrenador del fruto de la naranjilla $N$. elegantalis, se reporta al hongo entomopatógenos Beauveria bassiana atacando a pupas (Serrano, 1992); y, a la bacteria entomopatógena Bacillus thuringiensis que ataca a esta plaga principalmente en estado de larva (Cardona, 2008). Por la gran problemática presente en este cultivo este proyecto buscó una alternativa biológica para el control del barrenador del fruto de la naranjilla $N$. elegantalis que permita reducir la incidencia de la plaga y, al mismo tiempo, disminuir la utilización de productos nocivos para el ambiente. Por lo expuesto, se planteó el estudio para evaluar la eficiencia del uso de extractos vegetales y agentes microbiológicos para el control del barrenador del fruto de naranjilla $N$. elegantalis.

Específicamente se buscó determinar el tratamiento más efectivo; establecer la capacidad de control de los agentes microbiológicos; e, identificar el extracto vegetal de mayor eficiencia en el control del barrenador del fruto de la naranjilla $N$. elegantalis.

\section{Materiales y métodos}

Esta investigación se llevó a cabo en dos fases denominadas campo y laboratorio. La fase de laboratorio se desarrolló en los laboratorios del Departamento Nacional de Protección vegetal (DNPV), específicamente en el área de Entomología y Control Biológico del Instituto Nacional de Investigaciones Agropecuarias-Estación Experimental Santa Catalina, localizado en la provincia: Pichincha, cantón: Mejía, parroquia: Cutuglagua a 3,050 m.s.n.m., Latitud: $00^{\circ} 22^{\prime} \mathrm{S}$, Longitud: $78^{\circ} 33^{\prime} \mathrm{O}$. En cuanto a las condiciones de laboratorio se manejó una temperatura promedio de $11.7^{\circ} \mathrm{C}$ y una humedad relativa promedio de $83.62 \%$. Los tratamientos evaluados para determinar la mortalidad de huevecillos así como larvas de primer estadio de la polilla de la cera (Galleria mellonella Lepidóptera: Pyrlidae) fueron: $\mathrm{t}_{1}\left(\right.$ Ecofoliar $\left.^{\circledR} 7.5 \mathrm{~cm}^{3} / \mathrm{dm}^{3}\right), \mathrm{t}_{2}\left(\right.$ Vértigo $^{\circledR} 3.8 \mathrm{~cm}^{3} /$ $\left.\mathrm{dm}^{3}\right), \mathrm{t}_{3}\left(\operatorname{Nexus}^{\circledR} 3.8 \mathrm{~cm}^{3} / \mathrm{dm}^{3}\right), \mathrm{t}_{4}\left(\operatorname{Biosan}^{\circledR} 3 \mathrm{~cm}^{3} /\right.$ $\left.\mathrm{dm}^{3}\right), \mathrm{t}_{5}$ (Piñón $5 \mathrm{~cm}^{3} / \mathrm{dm}^{3}$ ). Galleria mellonella fue utilizada como sujeto de estudio para determinación de mortalidad debido a que no se pudo realizar la cría de Neoleucinodes elegantalis bajo condiciones de laboratorio. Los tratamientos que mayor mortalidad generaron, tanto en huevecillos como larvas de primer estadio fueron evaluados en campo, donde adicionalmente se evaluó al hongo entomopatógeno Beauveria bassiana cepa 64 proveniente del Departamento de Control Biológico del Instituto Nacional de Investigaciones Agropecuarias (INIAP-ESSC) y la bacteria entomopatógena Bacillus thuringiensis evaluadas en investigaciones anteriores, con controles de $34 \%$ y $59 \%$ respectivamente (Gallegos, Simbaña \& Asaquibay, 2013).

La unidad experimental constó de una caja de plástico de $3 \mathrm{~cm} \times 3 \mathrm{~cm}$ en la cual se colocó una sección de panal de aproximadamente $2 \mathrm{~cm}$, el mismo que previamente fue sumergido en la solución de cada extracto, durante 2 minutos (Maiguascar, 2002). En el caso de la variable mortalidad de larvas de primer estadio la evaluación fue realizada a los tres días y a los cinco días después de la aplicación del tratamiento. Para la variable mortalidad de huevecillos la evaluación se realizó hasta la eclosión de los mismos donde se tomó en cuenta el número de huevecillos eclosionados en relación con el testigo, el dato obtenido fue expresado en porcentaje; la aplicación de los tratamientos en ambas variables fue directa y se aplicó una sola vez. Cada unidad experimental estuvo provista por 10 individuos. En esta fase se utilizó un diseño completamente al azar 
(DCA) con cuatro observaciones. Se realizó el ajuste de los datos de mortalidad a partir de los datos obtenidos en el testigo utilizando la fórmula de Abbott (Tabla 1).Adicionalmente, se realizó el análisis funcional utilizando la prueba de Tukey al $\mathrm{p}<0.01$ debido a que se presentaron diferencias altamente significativas en el análisis de varianza (Tabla 2).

La segunda parte de la investigación denominada fase de campo se llevó a cabo en la finca de la señora Teresa Ortiz ubicada en la provincia: Tungurahua, cantón: Baños, parroquia: Río Negro a 1,230 m.s.n.m., Latitud: $1^{\circ} 24^{\prime} 27.33^{\prime \prime}$ S, Longitud: $78^{\circ} 11^{\prime} 27.57^{\prime \prime} \mathrm{O}$, con una temperatura promedio anual de $21^{\circ} \mathrm{C}$ y una precipitación promedio anual de 3,600 $\mathrm{mm}$. Los tratamientos evaluados fueron $\mathrm{T} 1$ (Ecofoliar ${ }^{\circledR} 7.5 \mathrm{~cm}^{3} / \mathrm{dm}^{3}$ ), T2 (Vértigo ${ }^{\circledR} 3.8 \mathrm{~cm}^{3} / \mathrm{dm}^{3}$ ), T3 $\left(\right.$ Biosan $^{\circledR} 3 \mathrm{~cm}^{3} / \mathrm{dm}^{3}$ ), T4 (Piñón $5 \mathrm{~cm}^{3} / \mathrm{dm}^{3}$ ), T5 (Bacillus thuringiensis $2.5 \mathrm{~cm}^{3} / \mathrm{dm}^{3}$ ), T4 (Beauveria bassiana concentración $\left.1 \times 10^{8}\right)$ a los que se les adicionó un coadyuvante (Silwet L- $77 \mathrm{Ag}$ con dosis de $0.15 \mathrm{~cm}^{3} / \mathrm{dm}^{3}$ ) y un regulador de $\mathrm{pH}$. (Indicate 5) al momento de la aplicación. Los tratamientos fueron aplicados cada 8 días.

La unidad experimental constó de dos plantas híbrido Puyo, donde las variables evaluadas fueron: número de frutos por planta y por mes a la cosecha, número de frutos sanos cosechados al mes por planta, número de frutos infestados por planta y por mes; $\mathrm{y}$, porcentaje de frutos sanos cosechados al mes por planta. A su vez, se realizó un análisis estadístico para los datos acumulados mensuales por cada variable. Para este trabajo se utilizó un diseño de bloques completos al azar DBCA con tres repeticiones, donde las evaluaciones se realizaron a la cosecha mensual. Se realizó el ANOVA por variable, aplicando pruebas de Tukey $(\mathrm{p}<0.01)$ debido a que presentaron diferencias altamente significativas en el análisis de varianza.

\section{Resultados y discusión}

\subsection{Fase de laboratorio}

\subsubsection{Porcentaje de mortalidad de huevecillos}

En la Tabla 1 se observa que existen diferencias significativas para extractos vegetales. La mortalidad promedio de huevecillos fue $17.50 \%$ y un C.V. $=$ $23.12 \%$. Cabe mencionar que los datos obtenidos para esta variable no presentaron homogeneidad, por lo que se procedió a realizar transformación de datos con raíz cuadrada $(\sqrt{x+1})$ para posteriormente realizar el análisis de la varianza. La prueba de Tukey para porcentaje de mortalidad de huevecillos de $G a$ lleria mellonella (Tabla 2 y Figura 1) presentaron diferentes rangos estadísticos, en los cuales se destaca $\mathrm{t}_{5}$ (Aceite de piñón) con una mortalidad de 30\%.

3.1.2 Porcentaje de mortalidad de larvas de primer estadio a los 3 y 5 días

Existen diferencias significativas entre tratamientos (Tabla 1). El promedio general en cuanto a mortalidad de larvas de primer estadio, a los tres días, es de $61.44 \%$; y un C.V. $=17.24 \%$. El promedio general para mortalidad de larvas de primer estadio, a los cinco días, es de $76.17 \%$ y un C.V $=8.74 \%$. Cabe destacar que ambos coeficientes de variación se consideran muy buenos para este tipo de investigación.

Las pruebas de Tukey para porcentaje de mortalidad de larvas de primer estadio a los tres y cinco días (Tabla 2 y Figura 3) presentaron diferentes rangos estadísticos, entre los cuales se destacó T5 (Aceite de Piñón), con una mortalidad de $86.39 \%$, a los tres y cinco días de evaluación; seguido de T1 $\left(\right.$ Ecofoliar $^{\circledR}$ ) con un porcentaje de $59.63 \%$ a los tres y cinco días, induciendo una mortalidad de $83.61 \%$.

Tabla 1. Cuadrados medios para mortalidad de huevecillos y larvas de primer estadio de Galleria mellonella, en la evaluación de extractos vegetales y agentes microbiológicos para el control del barrenador de la naranjilla (Neoleucinodes elegantalis).

\begin{tabular}{|c|c|c|c|c|}
\hline \multicolumn{2}{|c|}{ Fuentes de Variación } & \multicolumn{3}{|c|}{ Cuadrados medios } \\
\hline & & $\begin{array}{c}\text { Mortalidad de huevecillos } \\
(\%)\end{array}$ & $\begin{array}{c}\text { Mortalidad de larvas a } \\
\text { los } \mathbf{3} \text { días } \\
(\%)\end{array}$ & $\begin{array}{c}\text { Mortalidad de } \\
\text { larvas a los } 5 \text { días } \\
(\%)\end{array}$ \\
\hline \multicolumn{2}{|c|}{$\begin{array}{l}\text { Tratamientos } \\
\text { Error }\end{array}$} & $\begin{array}{l}0.76 * * \\
0.05\end{array}$ & $\begin{array}{l}855.05^{* *} \\
112.27\end{array}$ & $\begin{array}{l}453.86^{* *} \\
44.29\end{array}$ \\
\hline Promedio & $(\%)$ & 17.50 & 61.45 & 76.17 \\
\hline$C V$ & $(\%)$ & 23.12 & 17.24 & 8.74 \\
\hline
\end{tabular}




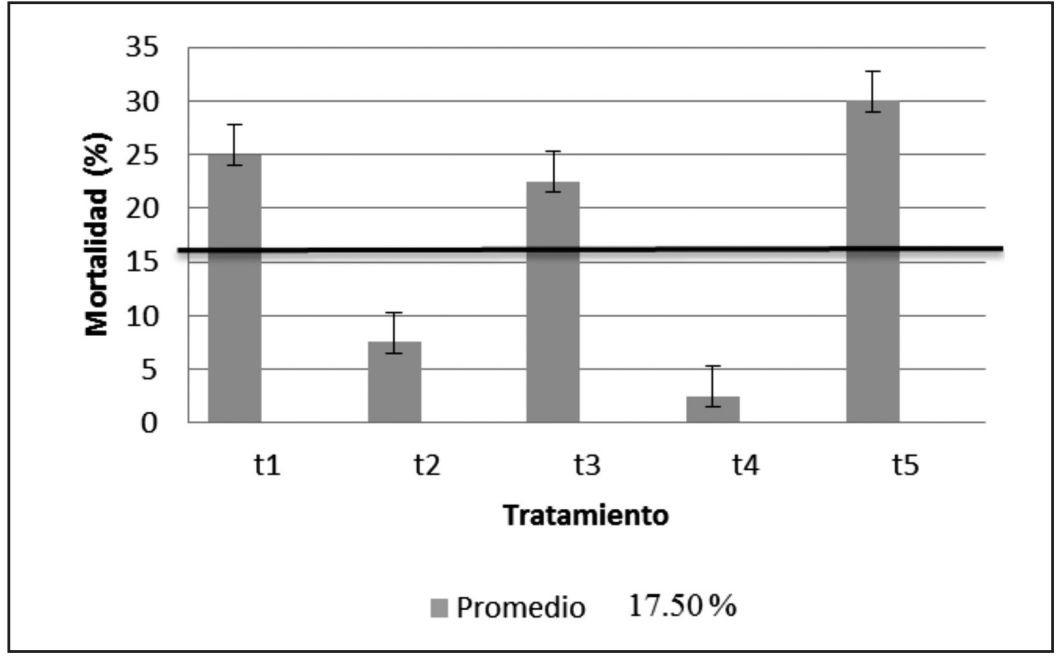

Figura 1. Porcentaje de mortalidad de huevecillos de Galleria mellonella y error estándar en la evaluación de extractos vegetales y agentes microbiológicos para el control de Neoleucinodes elegantalis.

Tabla 2. Rangos de significancia (Tukey $\mathrm{p}<0.01$ ) del porcentaje de mortalidad de huevecillos, porcentaje de mortalidad a los tres días y cinco días de larvas de Galleria mellonella, en la evaluación de extractos vegetales y agentes microbiológicos.

Mortalidad de huevecillos (\%)

Medias (\%)

Rangos de significancia

(T5) Aceite de piñón

(T1) Ecofoliar ${ }^{\circledR}$

(T3) Biosan ${ }^{\circledR}$

(T2) Vértigo ${ }^{\circledR}$

(T4) Nexus ${ }^{\circledR}$
30.00

25.00

22.50

7.50

2.50

\section{a}

a

$\mathrm{a} b$

b c

c

Mortalidad de larvas a los 3 días (\%)
(T5) Aceite de piñón
(T1) Ecofoliar ${ }^{\mathbb{B}}$
(T3) Biosan ${ }^{\circledR}$
(T2) Vértigo
(T4) Nexus ${ }^{\circledR}$

ñón

86.39

59.73

59.45

51.67

50.00 b

b

b

Mortalidad de larvas a los 5 días (\%)
(T5) Aceite de Piñón
(T1) Ecofoliar ${ }^{\circledR}$
(T3) Biosan ${ }^{\circledR}$
(T2) Vértigo ${ }^{\circledR}$
(T4) Nexus ${ }^{\circledR}$

86.39

83.61

78.34

73.06

59.45

$\begin{array}{ll}a & \\ a & \\ a & \\ a & b \\ & b\end{array}$




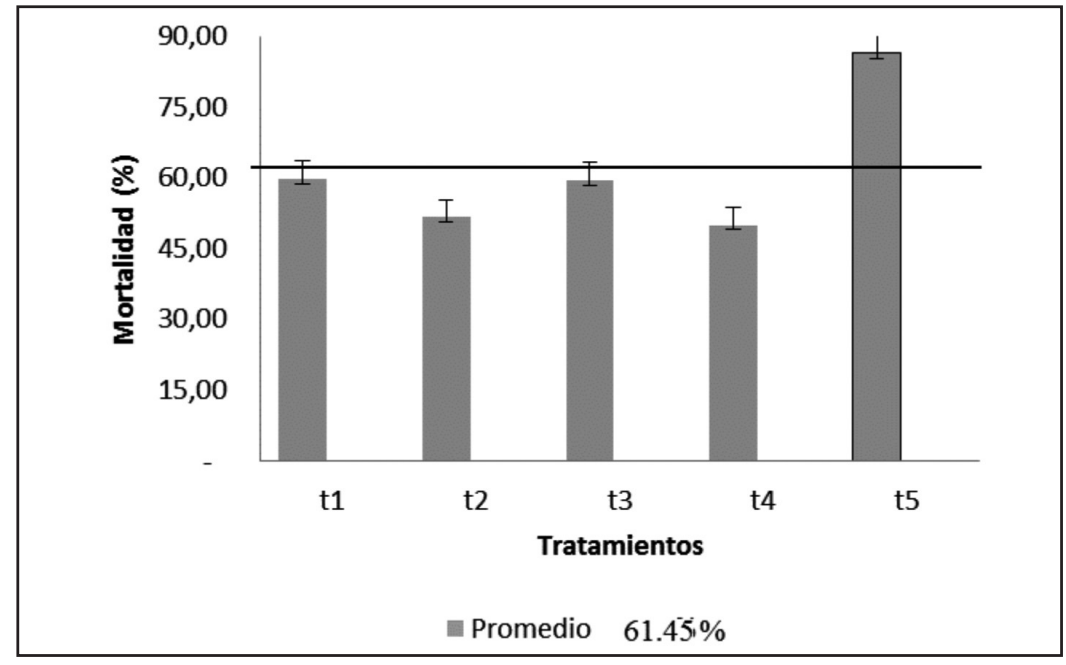

Figura 2. Porcentaje de mortalidad de larvas de Galleria mellonella y error estándar a los tres días en la evaluación de extractos vegetales y agentes microbiológicos para el control de Neoleucinodes elegantalis, Cutuglahua, Pichincha, 2015.

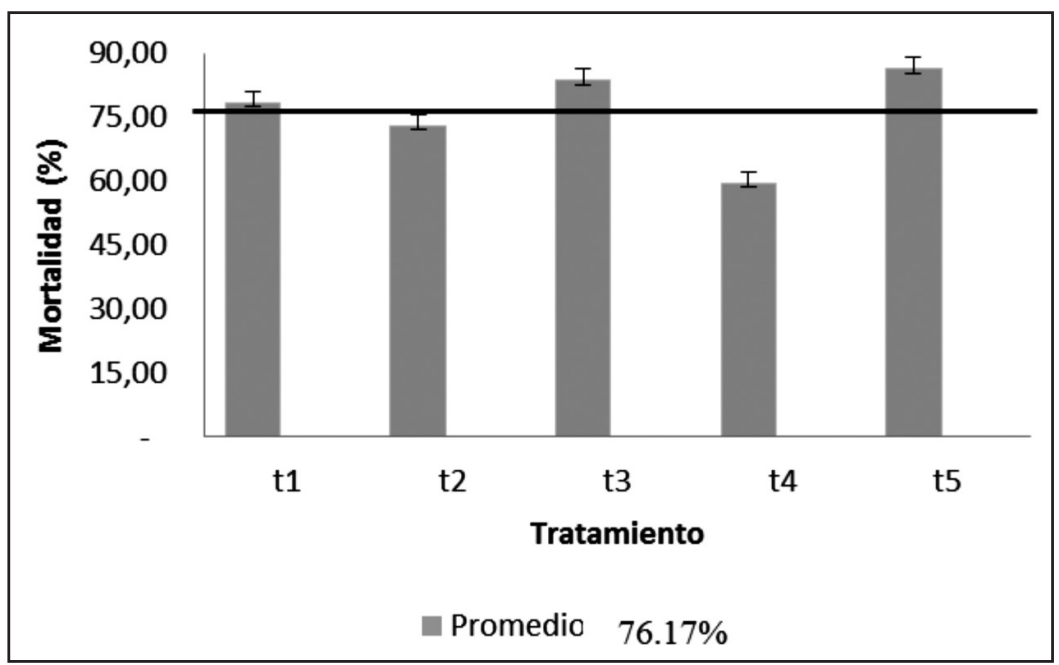

Figura 3. Porcentaje de mortalidad de larvas de Galleria mellonella y error estándar a los cinco días en la evaluación de extractos vegetales y agentes microbiológicos para el control de Neoleucinodes elegantalis.

Partiendo del dato de mortalidad del mejor tratamiento T5 (Aceite de piñón), se puede inferir que la susceptibilidad de huevecillos frente a la acción de los aceites es mayor en huevecillos jóvenes que en huevecillos maduros, conforme a lo encontrado por Trammel (1965); sin embargo, hay varios factores que pueden influir en el porcentaje de mortalidad, como las características fisicoquímicas propias de los aceites, tales como densidad y viscosidad según lo sostiene Ferrero et al. (2001). En el presente estudio, los huevecillos fueron sometidos a una sola aplicación del tratamiento, por lo que la acción en cuanto a control se presentó dentro de los primeros días del desarrollo embrionario (Buteler \& Stadler, 2011). Adicionalmente, Ferrero et al. (2001) citando a Smith \& Pearce (1948) mencionan que el efecto ovici- da de los aceites se produce a través del "descenso de la tasa respiratoria" así como la interferencia mecánica en el proceso normal de intercambio gaseoso; pero para que se genere un control por parte del aceite es necesario que permanezca en contacto con el corion del huevecillo por un lapso de tiempo de 24 horas.

Siguiendo con el análisis de los resultados Ecofoliar $^{\circledR}$ (T1), la evaluación a los 3 días presentó una mortalidad de larvas de primer estadio de $59.73 \%$ (Tabla 2), mientras que para la evaluación de mortalidad a los 5 días aumentó al 78.34\% (Figura 2). Esto se debe a la característica propia del producto que actúa inhibiendo el proceso de alimentación del insecto.

Por otro lado, Biosan ${ }^{\circledR}$ (T3) presentó una mortalidad de $78.34 \%$ (Figura 2). Este tratamiento actúa 
a nivel del sistema nervioso, sistema respiratorio y sistemas circulatorio (Edifarm, 2008). Como se puede observar en la Tabla 2, este tratamiento presentó una mortalidad inicial de $59.45 \%$ para luego alcanzar 78.34\%, a los cinco días de evaluación; esto se debe a que el producto actúa al nivel de sistema respiratorio generando una "alteración del metabolismo energético y la pérdida subsecuente de ATP" provocando la inactividad, parálisis y posterior muerte del insecto (Bloomquist, 2003).

De acuerdo con los datos obtenidos en la fase de laboratorio se puede inferir un posible control exitoso por parte de los tratamientos, por lo que fueron seleccionados para la fase de campo siendo éstos: T1 (Ecofoliar ${ }^{\circledR} 7.5 \mathrm{~cm}^{3} / \mathrm{dm}^{3}$ ), T2 (Vértigo ${ }^{\circledR} 3.8 \mathrm{~cm}^{3} /$ $\mathrm{dm}^{3}$ ), T3 $\left(\right.$ Biosan $^{\circledR} 3 \mathrm{~cm}^{3} / \mathrm{dm}^{3}$ ), T4 (Piñón $5 \mathrm{~cm}^{3} /$ $\left.\mathrm{dm}^{3}\right)$; y, adicionalmente se evaluaron a T5(Bacillus thuringiensis $2,5 \mathrm{~cm}^{3} / \mathrm{dm}^{3}$ ), y T6 (Beauveria bassiana concentración $1 \times 10^{8}$ ).

\subsection{Fase de campo}

\subsubsection{Número de frutos totales por planta}

La Tabla 3 presenta el análisis de varianza para número de frutos totales acumulados. Existen diferencias significativas para tratamientos. El promedio general para esta variable es de 24 frutos/ 4 cosechas y su coeficiente de variación fue de $6.28 \%$. La prueba de Tukey reportó la existencia de dos rangos, siendo T2 (Vértigo ${ }^{\circledR}+$ Ac. Piñón)el mejor tratamiento con 27.92 frutos/ 4 cosechas.

\subsubsection{Número de frutos sanos por planta}

Existen diferencias significativas entre tratamientos para el número de frutos sanos acumulados. El promedio general de número de frutos fue de 10 y el coeficiente de variación fue de $13.53 \%$. Las pruebas de Tukey detectaron la existencia de 4 rangos de significancia, siendo T2, T5 y T1 los mejores tratamientos.

\subsubsection{Número de frutos infestados por planta}

Existen diferencias significativas para el número de frutos infestados. El promedio general para esta variable fue de 14 frutos por planta. Las pruebas de Tukey detectaron la presencia de 3 rangos de significancia. T2, T1, T5 y T3, en ese orden, exhibieron los mejores resultados, por contraparte, el tratamiento testigo T7 presentó los resultados más pobres.

\subsubsection{Porcentaje de fruta sana}

En el análisis de la varianza para porcentaje de frutos sanos acumulados se aprecia que existen diferencias significativas para tratamientos. El promedio general fue de $41.17 \%$ y su C.V $=9.74 \%$. Las pruebas de Tukey reportaron la existencia de tres rangos, en el primero de los cuales se ubicaron T2 (Vértigo+ Ac. Piñón), con $51.41 \%$ y T5 (Bacillus thuringiensis) con $50.56 \%$ frutas sanas.

Tabla 3. Cuadrados medios para número de frutos sanos, número de frutos infestados, número de frutos totales y porcentaje de frutos sanos acumulados en cuatro cosechas consecutivas, en la evaluación de extractos vegetales y agentes microbiológicos para el control de Neoleucinodes elegantalis.

\begin{tabular}{lcccc}
\hline & \multicolumn{3}{c}{ Cuadrados medios } \\
\cline { 2 - 4 } & $\begin{array}{c}\text { Frutos } \\
\text { Sanos }\end{array}$ & $\begin{array}{c}\text { Frutos } \\
\text { infestados }\end{array}$ & $\begin{array}{c}\text { Frutos } \\
\text { Totales }\end{array}$ & $\begin{array}{c}\text { \% de fruta } \\
\text { sana }\end{array}$ \\
\hline Fuentes de Variación & $24.69^{* *}$ & $12.65^{* *}$ & $22.71^{* *}$ & $312.84^{* *}$ \\
Repetición & 1.52 & 0.49 & 0.50 & 12.61 \\
Error & 1.83 & 1.08 & 2.27 & 16.03 \\
\hline C.V. (\%) & 13.53 & 7.42 & 6.28 & 9.74 \\
Prom. Frutos/planta/4 cosechas & 10.00 & 14.00 & 24.00 & 41.10 \\
\hline
\end{tabular}

Como se puede observar en la Figura 4, el nivel de infestación fue variable en los meses de evaluación, siendo los meses de julio y agosto los que presentaron mayor infestación del barrenador del fruto Neoleucinodes elegantalis, a diferencia de los meses de septiembre y octubre donde los niveles de infestación descendieron drásticamente. Los niveles de control en la época lluviosa (julio y agosto), son sumamente bajos para todos los tratamientos, ya que no superan el $40 \%$ de control. La baja eficiencia de control por parte de los tratamientos puede deberse a factores como la precipitación, ya que dichos meses alcanzaron 10,78 y $8,85 \mathrm{~mm} /$ día, res- 
pectivamente. Al existir lluvias frecuentes el lavado de los productos aplicados fue inevitable (Nunes \& Leal, 2001), lo que redujo la eficiencia.

Para los meses secos, septiembre y octubre los niveles de control de $N$. elegantalis se incrementaron para todos los tratamientos incluido el testigo absoluto, el mismo que presentó sanidad a un $46.48 \%$ entre los dos meses; lo que se debería a las condiciones climáticas existentes y a que las aplicaciones no se lavaban como en la época lluviosa. En general, los tratamientos que mejor eficiencia de control presentaron fueron $\mathrm{t}_{2}$ (Vértigo ${ }^{\circledR}+$ Ac. Piñón), con un $51.41 \%$ y como segundo mejor tratamiento, T5 (Bacillus thuringiensis), con un control de $50.56 \%$; tratamiento que presentó esta eficiencia sin adición de aceite de piñón.

El tratamiento $t_{2}\left(\right.$ Vértigo $^{\circledR}+$ Ac. Piñón) que presenta piretrinas como ingrediente activo tiene un mecanismo de acción cualitativamente similar al del
DDT y muchos otros insecticidas organoclorados que actúan principalmente al nivel de los axones neurales del insecto (Pérez, 2012). Por lo tanto, al provocar una actividad repetitiva en los nervios, en lugar de impulsos simples, alteran todo el sistema nervioso, causando incoordinación, hiperexcitación y parálisis del insecto (Pérez, 2012).

El segundo tratamiento que presentó buen comportamiento fue t5 (Bacillus thuringiensis) con $50,56 \%$ fruta sana. Estudios anteriores relacionados con el control ejercido por esta bacteria entomopatógena en el barrenador del fruto de la naranjilla $\mathrm{NeO}-$ leucinodes elegantalis han determinado un nivel de control de $59 \%$ en el cultivo de naranjilla (INIAP, 2009); por otro lado, la eficiencia de Bacillus thurigiensis también fue demostrada por Gravena (1989) citado en Nunes y Leal (2001) en el cultivo de tomate de mesa, a su vez mencionan que en época seca el porcentaje de pérdida por este insecto es de $5.28 \%$.

Tabla 4. Rangos de significancia (Tukey $\mathrm{p}<0.01$ ) para número de frutos totales, frutos sanos, frutos infestados y porcentaje de frutos sanos acumulados en cuatro cosechas, en la evaluación de extractos vegetales y agentes microbiológicos.

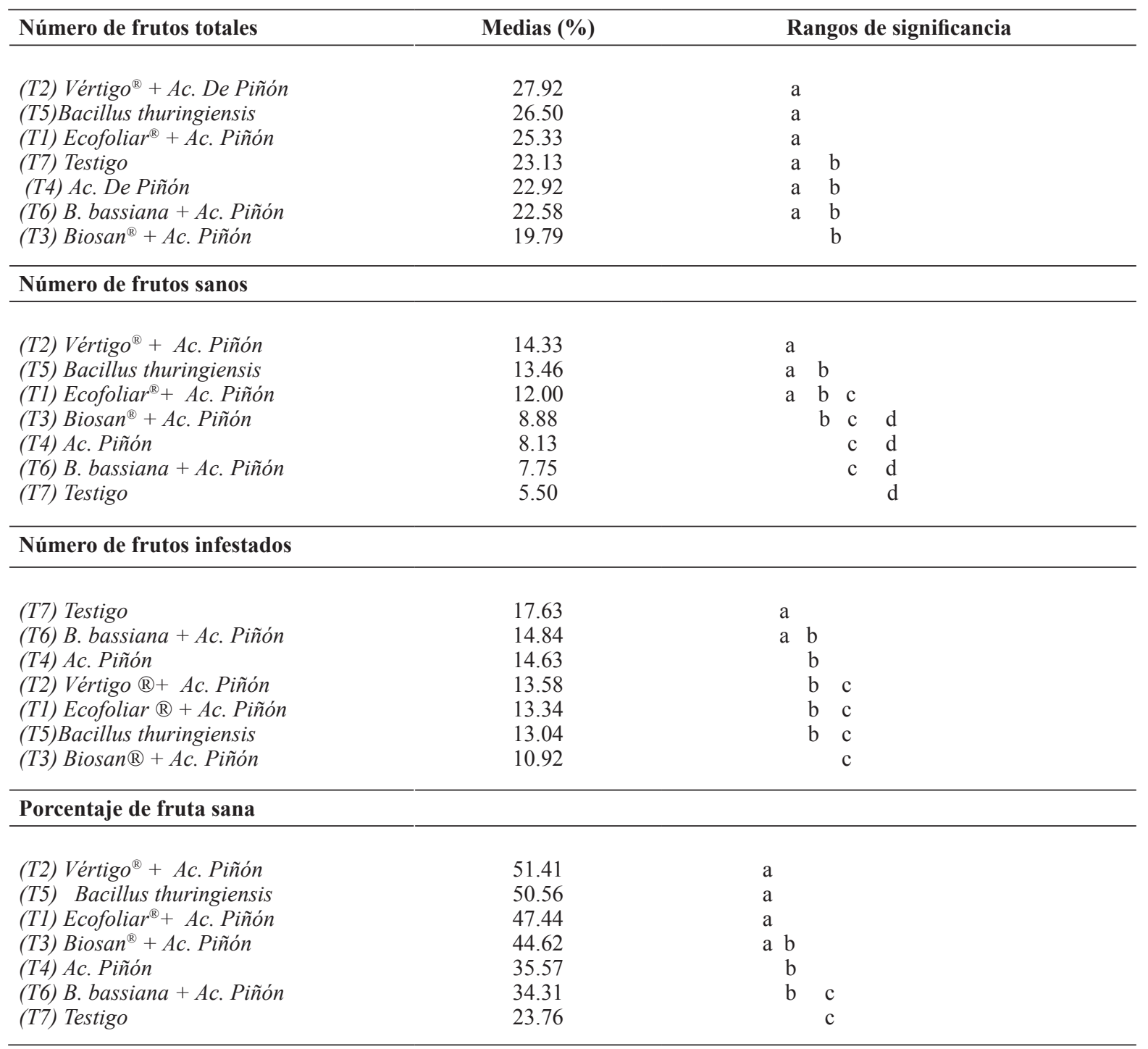




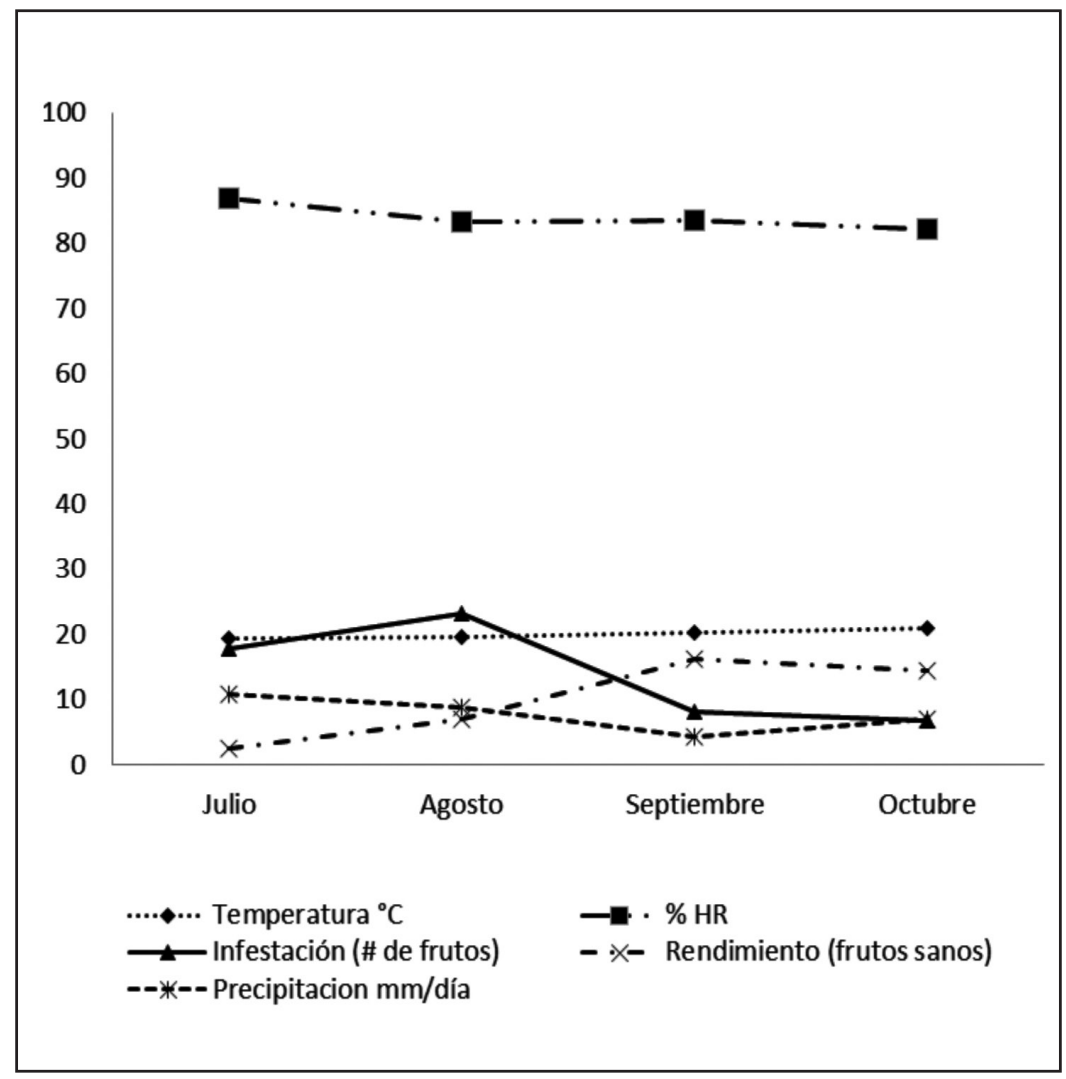

Figura 4. Rendimiento de frutos sanos mensuales en cuatro cosechas consecutivas, de acuerdo a temperatura, humedad relativa, precipitación e infestación, en la evaluación de extractos vegetales y agentes microbiológicos para el control de Neoleucinodes elegantalis.

Finalmente, Mirás, Issa y Jaffé (1997) citando a Marcano (1990) afirman que la alta y baja densidad poblacional de $N$. elegantalis en cultivo de tomate de mesa durante la época de lluvia y sequía, indica una estrecha relación de la fluctuación poblacional con los niveles de precipitación y humedad relativa. Presentando un porcentaje de frutos infestados de hasta el 50\% en épocas lluviosas y, un por-

\section{Referencias}

Bloomquist, J. (2003). El texto Mundial del MIP.

Buteler, M., \& Sladler, T. (2011). A Review on the Mode of Action and Current use of Petroleum Distilled Spray Oils. Stoytcheva (Ed.), Isticides in the Modern World - Pests Control and Pesticides Exposure and Toxicity Assessment. Mendoza, Argentina: INTECH. centaje de frutos dañados, de $11 \%$, en épocas secas. Por su parte, Lanza (2011) y Bonilla, (1996) producto de estudios sobre del barrenador del fruto Neoleucinodes elegantalis en tomate de mesa Lycopersicon esculentum, argumentan que las poblaciones de $N$. elegantalis en el campo son mayores en época de lluvia que en época de sequía; sin embargo, existe variabilidad a través del tiempo y el espacio.

Díaz, A., \& Brochero, H. (2012). Parasitoides asociados al perforador del fruto de las solanáceas Neoleucinodes elegantalis (Lepidoptera: Crambidae) en Colombia. Revista Colombiana de Entomología, 38 (1), 50-57.

EDIFARM. (2008). Vademécum Agrícola. Quito, Ecuador.

Ferrero, A., Cariac, M., Gutiérrez, M., Laumann, R., \& Cervellini, P. (2001). Evaluación en laboratorio de 
un aceite mineral y extractos crudos vegetales en huevos y adultos de Cydia pomonella L.(Lepidóptera: Tortricidae, gusano del manzano). Boletin Sanidad Vegetal Plagas, 27.

Fiallos, J. (2000). Naranjilla. INIAP - Palora. Híbrido interespecífico de alto rendimiento. Boletín divulgativo $\mathrm{N}^{\circ} 276$. Quito, Ecuador: INIAP

Gallegos, P., Simbaña, L., Asaquibay., C. (2013). Manejo Integrado de Plagas Ciencia para el desarrollo Agrícola de América Latina y el Caribe. Informe de actividades. DNPV. Quito, Ecuador: INIAP.

Instituto Nacional Autónomo de Investigaciones Agropecuarias. (2009). Comportamiento y alternativas de control del gusano del fruto de la naranjilla ( $N$. elegantalis). Quito, Ecuador: INIAP.

Lanza, J. (2011). Sistema de comunicación de la plaga de tomate Neoleucinodes elegantalis (Lepidóptera: Crambidae).

Maiguascar, F. (2002). Efecto de ocho insecticidas de baja toxicidad para mamíferos en el control de adulto de gusano blanco de la papa Premnotrypes vorax. Quito, Ecuador: INIAP - EESC.

Ministerio de Agricultura, Ganadería, Acuacultura y Pesca INEC-MAG-SICA. (2012). Sistema de Información Nacional de Agricultura, Ganadería, Acuacultura y Pesca. Obtenido de SINAGAP: http://sinagap. agricultura.gob.ec/index.php/resultados-nacionales/ file/59-censo-nacional.

Molina, S., Manzano, M. (2012). Neoleucinodes elegantalis (Lepidoptera:Crambidae) plaga de Solanum quitoense. ¿Es vulnerable al control el primer estadio larval? Acta Agronómica. Número especial. 61-62

Miras, B., Issa, S., Jaffé, K. (1997). Diseño y evaluación de trampas cebadas con hembras vírgenes para la captura del perforador del fruto del tomate. Caracas, Venezuela: Agronomía Tropical, 47(3), 315-330.

Núnes, M. U., \& Leal, M. L. (2001). Effect of biofertilizer, and others biological and chemical products, in controlling the fruit small driller and in the production of staked tomato in two planting seasons and two irrigation systems. Horticultura Brasileira, 19(1), 20-23.

Pérez López, E. (2012). Plaguicidas botánicos: una alternativa a tener en cuenta. La Habana, Cuba: Fitosanidad 16(1), 51-59.

Tipanluisa, S. (2011). Evaluación de dos métodos de control (Práctica cultural y Microorganismos) contra Fusarium oxysporum en el cultivo de naranjilla (Solanum quitoense). CHACO - NAPO.

Trammel, K. (1965). Properties of petroleum oils in relation to performance as citrus tree sprays in Florida. Obtenido de Internet Archieve University of Florida : http://archive.org/stream/propertiesofpetr00tram/propertiesofpetr00tram_djvu.txt

Revelo, J., Viteri, P., Wilson, V., Valverde, F., León, J., \& Gallegos, P. (2010). Manual del cultivo ecológico de la naranjilla.Quito, Ecuador: Manual Técnico No 77.

Ruiz, L. (2013). Situación actual de las frutas amazonicas del Ecuador. Obtenido de Slideshare: http:// es.slideshare.net/MarC4585/situacion-de-las-frutas-amazonicas-Ecuador 